\title{
DNA G-quadruplexes for native mass spectrometry in potassium: a database of validated structures in electrospray-compatible conditions
}

\author{
Anirban Ghosh, Eric Largy* and Valérie Gabelica ${ }^{\left({ }^{*}\right.}$ \\ Univ. Bordeaux, CNRS, INSERM, ARNA, UMR 5320, U1212, IECB, F-33000 Bordeaux, France
}

Received November 07, 2020; Revised December 22, 2020; Editorial Decision January 09, 2021; Accepted January 19, 2021

\begin{abstract}
G-quadruplex DNA structures have become attractive drug targets, and native mass spectrometry can provide detailed characterization of drug binding stoichiometry and affinity, potentially at high throughput. However, the G-quadruplex DNA polymorphism poses problems for interpreting ligand screening assays. In order to establish standardized MS-based screening assays, we studied 28 sequences with documented NMR structures in (usually $\sim 100 \mathrm{mM}$ ) potassium, and report here their circular dichroism (CD), melting temperature $\left(T_{\mathrm{m}}\right)$, NMR spectra and electrospray mass spectra in $1 \mathrm{mM} \mathrm{KCl} / 100 \mathrm{mM}$ trimethylammonium acetate. Based on these results, we make a short-list of sequences that adopt the same structure in the MS assay as reported by NMR, and provide recommendations on using them for MSbased assays. We also built an R-based open-source application to build and consult a database, wherein further sequences can be incorporated in the future. The application handles automatically most of the data processing, and allows generating custom figures and reports. The database is included in the g4dbr package (https://github.com/EricLarG4/g4dbr) and can be explored online (https://ericlarg4.github. io/G4_database.html).
\end{abstract}

\section{INTRODUCTION}

Nucleic acids constitute the fundamental biomolecular machinery to transfer genetic information, but are also involved in the regulation of gene expression (1). Besides the canonical double helix, nucleic acids can adopt various non-canonical structures, i.e. triplexes, slipped hairpins, four-way junctions, left-handed Z-form, cruciform, Gquadruplexes or i-motifs (2). G-quadruplexes (G4s) have been the subject of intense structural and biological research, given their roles in gene regulation and other re- lated cellular processes $(3,4)$. G4s indeed have important biological effects in replication, transcription, translation, mutagenesis, genome damage repair, telomere maintenance, or RNA splicing $(3,5,6)$. Their key role in different cellular processes makes them crucial drug targets for diseases (68). Besides biological roles, G4s have also numerous other applications in theranostics, supramolecular chemistry, or nanotechnology (6,9-12).

The building block is a G-quartet wherein four guanines adopt a square planar arrangement stabilized by eight Hoogsteen hydrogen bonds (4). The stacking of adjacent Gquartets is further stabilized by coordination with monovalent or divalent cations positioned in-between G-quartets $(4,13)$. The guanine repeats are connected by loops. The G4 topologies are conveniently categorized as parallel (four strands in the same direction, all-anti homo-stacking), antiparallel (two strands in one direction and two in the other direction, alternate syn/anti hetero-stacking) and hybrid (three strands in one direction and one strand in the reverse direction, combination of homo and hetero stacking). Further sub-classes can be defined depending on the number of G-quartets, or which loop is lateral, diagonal or propeller. These topologies are themselves linked with the conformation of the glycosidic bond angle between the guanine base and sugars, to the stacking arrangement giving rise to specific circular dichroism signals, and to the groove width distribution $(14,15)$.

Various analytical methods are routinely used to characterize G4 structures and their interaction with ligands (small molecule, proteins, cations, co-solvents etc.). Each experimental technique has inherent limitations in terms of analytes (e.g. oligonucleotide size, concentration, thermodynamic stability, labeling), buffers (e.g. cation nature and concentration, ionic strength, $\mathrm{pH}$, volatility), and conditions (e.g. temperature, pressure). Studies on human telomeric sequences (TTAGGG repeats), in particular, have revealed that minor changes in the oligonucleotide sequence or in the buffer conditions can alter the structure. At least eight different types of intramolecular G4 topologies were identified to date and some sequences are inher-

\footnotetext{
*To whom correspondence should be addressed. Tel: +33 54000 2940; Email: valerie.gabelica@inserm.fr Correspondence may also be addressed to Eric Largy. Tel: +33 54000 6331; Email: eric.largy@u-bordeaux.fr
}

(C) The Author(s) 2021. Published by Oxford University Press on behalf of Nucleic Acids Research.

This is an Open Access article distributed under the terms of the Creative Commons Attribution License (http://creativecommons.org/licenses/by/4.0/), which permits unrestricted reuse, distribution, and reproduction in any medium, provided the original work is properly cited. 
ently polymorphic $(13,16,17)$. In the absence of external factors (i.e. co-solvents, proteins), the nature and concentration of cations predominantly affect the G4 conformation of a given sequence $(18,19)$. A seminal example of this issue is the 22-mer human telomeric sequence (22AG in this manuscript), which has been assigned as a parallel G4 by crystallography in potassium conditions (PDB: 1KF1), an antiparallel G4 by NMR in sodium conditions (PDB: 143D), and a mixture of topologies (hybrid \& antiparallel) in circular dichroism of potassium-containing solutions (20-22). The comparison of results obtained by different groups, using different methods and/or experimental conditions might therefore not always be directly possible, and should always be questioned.

In this manuscript, we attempt to facilitate such comparisons by native electrospray mass spectrometry (ESI-MS) (23-25). Native MS of nucleic acids and proteins is often performed in ammonium acetate $\left(\mathrm{NH}_{4} \mathrm{OAc}\right)$, but although $\mathrm{NH}_{4} \mathrm{OAc}$ is compatible with $\mathrm{G} 4$ formation $(24,26)$, potassium is more physiologically relevant, and consequently more $\mathrm{G} 4$ structures have been solved in $\mathrm{K}^{+}$solution. To directly compare native MS data to the literature, and to work with the physiologically relevant cation, it is therefore desirable to perform ESI-MS of potassium-containing samples. Since 2014, we use ESI-MS solutions containing up to 1 $\mathrm{mM} \mathrm{KCl}$ while the ionic strength is ensured by (typically 100 $\mathrm{mM}$ ) trimethylammonium acetate (TMAA), which can also more efficiently suppress nonspecific alkali adducts than $\mathrm{NH}_{4} \mathrm{OAc}$ (23). The number of $\mathrm{K}^{+}$ions bound to the sequence $(n)$ is related to the number of G-quartet in the observed sub-ensemble $(n+1)$, and thus the MS-derived $\mathrm{K}^{+}$ binding constants are linked to the G-quadruplex folding constants (27). This was exploited for equilibrium, kinetics, thermal denaturation and ligand binding studies $(22,28,29)$.

These electrospray-compatible solution conditions have not yet been used for systematic studies such as ligand screening. One possible limitation is that in $1 \mathrm{mM} \mathrm{K}^{+}$all the quadruplexes are less stable than in high salt $(\sim 100$ $\mathrm{mM} \mathrm{K} \mathrm{K}^{+}$) and as a result misfolded/alternative folded \& non folded species can form to a significant extent. Alternative sample preparation methods including co-solvents (hexafluoroisopropanol, isopropanol) have been proposed to increase the signal-to-noise ratio, but the risk is to induce conformational changes $(25,30,31)$. Therefore, in order to interpret the MS results in the light of an NMR- derived structure in $\mathrm{K}^{+}$we need to systematically verify by solution spectroscopy (CD, UV melting, and ${ }^{1} \mathrm{H}$ NMR) that the conformation reported in high salt conditions is also the one present in native MS conditions. The objective of the present study is to build a database of G4 sequences with sufficient stability and validated folds (based on UV melting, circular dichroism and NMR spectroscopies) in 1 $\mathrm{mM} \mathrm{KCl}+100 \mathrm{mM}$ TMAA assay conditions. This will help short-listing sequences for future MS-based ligand screening studies in terms of structural selectivity.

\section{MATERIALS AND METHODS}

\section{Materials}

Oligonucleotides were purchased in lyophilized form with RP cartridge purification from Eurogentec (Seraing, Bel- gium). They were dissolved in nuclease-free grade water from Ambion (Ambion, Life Technologies SAS, SaintAubin, Franc) to have a target concentration of $\sim 500 \mu \mathrm{M}$. The concentration of the stock solutions was determined using absorbance at $260 \mathrm{~nm}$ and molar extinction coefficients calculated using the nearest-neighbor model in its traditional format (Equation 1), where $\varepsilon_{i}$ is the molar extinction coefficient (in $\mathrm{M}^{-1} \mathrm{~cm}^{-1}$ ) of the nucleotide in position $i$ (in the $5^{\prime}$ to $3^{\prime}$ direction), $\varepsilon_{i, i+1}$ is the extinction coefficients for doublets of nucleotides in positions $i$ and $i+1$, and $N_{b}$ is the number of nucleotides in the oligonucleotide $(32,33)$.

$$
\varepsilon_{260 n m}=\sum_{i=1}^{N_{b}-1} \varepsilon_{i, i+1}-\sum_{i=2}^{N_{b}-1} \varepsilon_{i}
$$

The implementation of Equation (1) in the g4dbr application is provided in the g4dbr manual (Supporting information). All molar extinction coefficient values are provided in supporting information.

All sequences used in this study are listed in Table 1. Trimethylammonium acetate (TMAA, Ultra for UPLC, Fluka), potassium chloride solution (1 $\mathrm{M}$ concentration) $(\mathrm{KCl},>99.999 \%), \mathrm{KH}_{2} \mathrm{PO}_{4}$ and $\mathrm{K}_{2} \mathrm{HPO}_{4}$ (molecular biology grade), and $\mathrm{D}_{2} \mathrm{O}(99.9 \% \mathrm{D}$ atom) were purchased from Sigma-Aldrich (Saint-Quentin Fallavier, France). The stock oligonucleotide solutions were diluted to $100 \mu \mathrm{M}$ in 100 mM TMAA supplemented with $1 \mathrm{mM} \mathrm{KCl}$ in water $(\mathrm{pH}$ 7.0) and NMR buffer (Supplementary Table S1). They were kept at least $72 \mathrm{~h}$ at $4^{\circ} \mathrm{C}$ to ensure G-quadruplex formation. For telomeric sequences, no annealing was done, but previous studies showed that the end point will be reached after $72 \mathrm{~h}$ (22). For non-telomeric sequences, the solutions were annealed at $85^{\circ} \mathrm{C}$ for 3-4 min in a water bath then let at room temperature for $24 \mathrm{~h}$ before use. For UV melting and CD two buffers were used: (i) $100 \mathrm{mM}$ TMAA supplemented with $1 \mathrm{mM} \mathrm{KCl}$ (MS-compatible buffer) and (ii) 5$25 \mathrm{mM} \mathrm{K}_{2} \mathrm{HPO}_{4} / \mathrm{KH}_{2} \mathrm{PO}_{4}$ buffer supplemented with $\mathrm{KCl}$ (pH 7.0-7.1) (Supplementary Table S1).

\section{Circular dichroism (CD)}

All circular dichroism experiments were performed on a Jasco J-815 spectrophotometer equipped with a JASCO CDF 426S Peltier temperature controller using a quartz cuvette $\left(2 \mathrm{~mm}\right.$ path length) at $25^{\circ} \mathrm{C}$. The DNA concentration was $10 \mu \mathrm{M}$ for all the measurements. The scanning range was $220-320 \mathrm{~nm}$ with $0.2 \mathrm{~nm}$ data pitch, $2 \mathrm{~nm}$ bandwidth, and 0.5 -sec response. For each sample, 3 accumulations were acquired with a scan speed of $50 \mathrm{~nm} / \mathrm{min}$, then blankcorrected with the data from the corresponding buffer without DNA. The subtracted spectra were normalized to molar ellipticity coefficient $(\Delta \varepsilon)$ according to the following Equation (2):

$$
\Delta \varepsilon=\frac{\theta}{32980 \times C \times l}
$$

where $\theta=\mathrm{CD}$ signal in millidegrees, $C=\mathrm{DNA}$ concentration in $\mathrm{mol} / \mathrm{L}$, and $l=$ path length in $\mathrm{cm}$. 


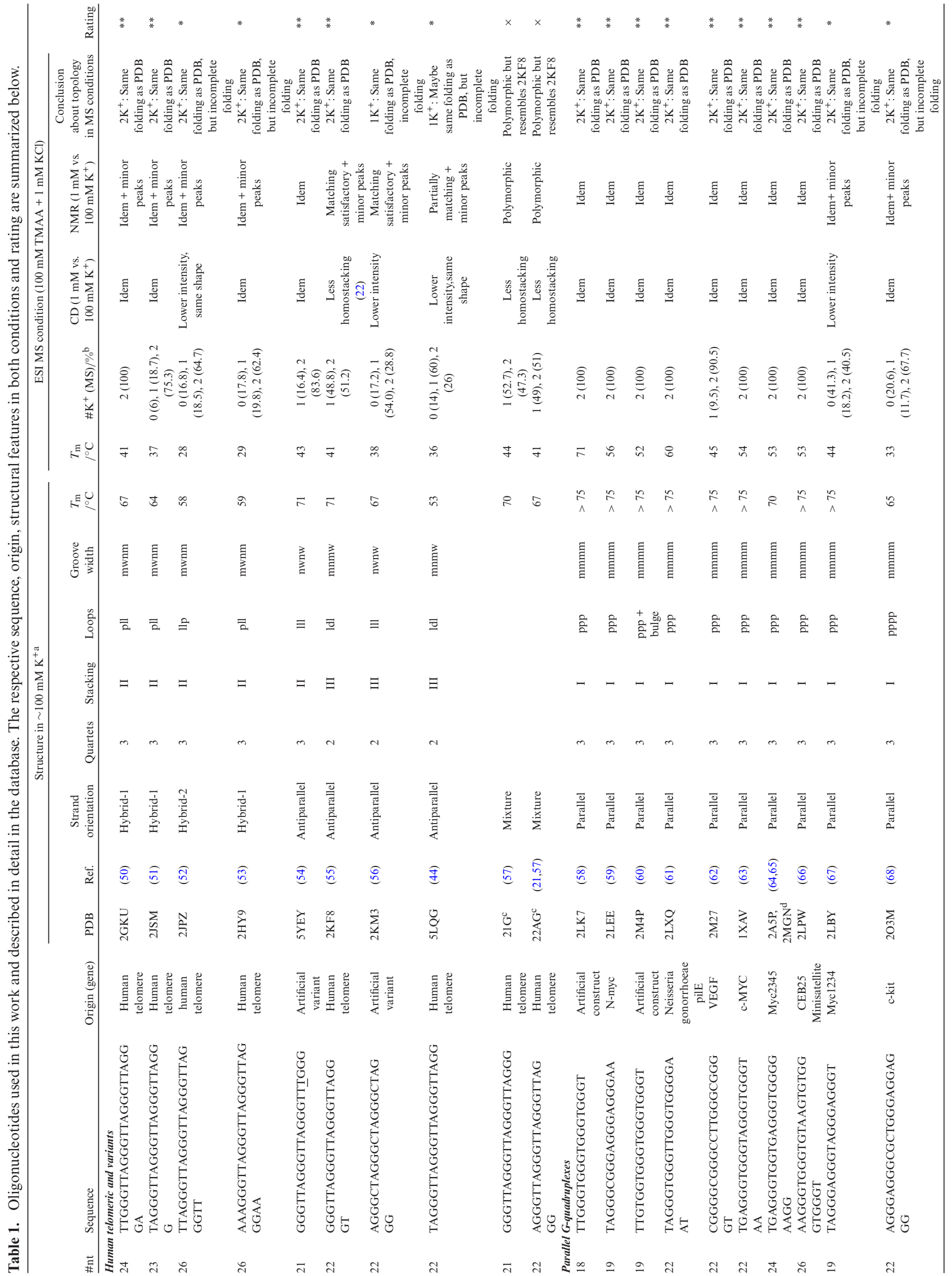




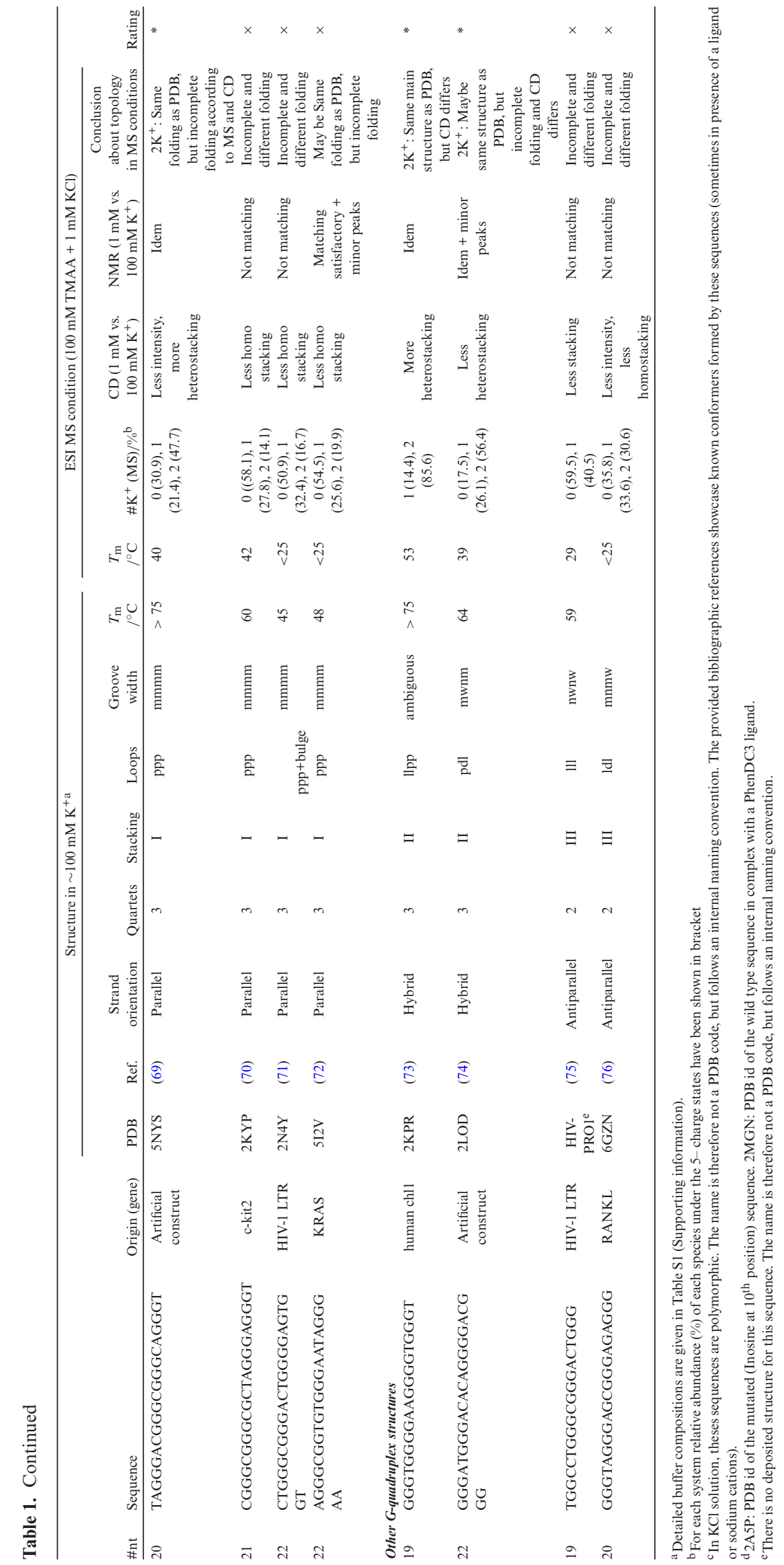




\section{Melting monitored by UV absorbance (UV-melting)}

Melting temperatures were determined by measuring the changes in absorbance at $295 \mathrm{~nm}$ as a function of temperature, using a UVmc2 double-beam spectrophotometer (SAFAS, Monte Carlo, Monaco) equipped with a highperformance Peltier temperature controller and a thermostatable 10-cell holder, with $400-\mu 1,1-\mathrm{cm}$ pathlength quartz cuvettes (115B-QS, Hellma GmbH \& Co. KG, Müllheim, Germany). The samples contained the oligonucleotide $(10 \mu \mathrm{M})$ in potassium phosphate or TMAA buffers, supplemented or not by potassium chloride, and were cooled to $4{ }^{\circ} \mathrm{C}$. The absorbance was monitored at 260 , 295 and $335 \mathrm{~nm}$ on a cycle composed of a heating to $90^{\circ} \mathrm{C}$ at a rate of $0.2^{\circ} \mathrm{C} \mathrm{min}{ }^{-1}$, then cooling to $4^{\circ} \mathrm{C}$ at the same rate.

The raw absorbance data was buffer subtracted, and converted to molar extinction coefficient $\varepsilon$ (in $\mathrm{M}^{-1} \mathrm{~cm}^{-1}$ ) using $\varepsilon=A / l C$, where $l$ is a path length (in $\mathrm{cm}$ ) and $C$ the oligonucleotide concentration (in $\mathrm{M}$ ). The melting temperatures $\left(T_{m}\right)$, determination for a 2-state equilibrium, and the conversion of the temperature-dependent absorbances $A_{T}$ into folded fractions $\theta_{T}$, were carried out based on a nonlinear fitting-based implementation of the baseline method, using Equation (3) where $a$ and $b$ are the slopes and intercepts, respectively, of the folded $(F)$ and unfolded $(U)$ baselines, $R$ is the gas constant (in $\mathrm{J} \mathrm{K}^{-1} \mathrm{~mol}^{-1}$ ), and $T$ is the temperature (in K) (34).

$$
\begin{aligned}
A_{T}= & \left(a^{F} T+b^{F}\right) \\
& \times \frac{1}{1+\exp \left(-\frac{\Delta H^{0}\left(1-\frac{T}{T_{m}}\right)}{R T}\right)}+\left(a^{U} T+b^{U}\right) \\
& \times \frac{\exp \left(-\frac{\Delta H^{0}\left(1-\frac{T}{T_{m}}\right)}{R T}\right)}{1+\exp \left(-\frac{\Delta H^{0}\left(1-\frac{T}{T_{m}}\right)}{R T}\right)}
\end{aligned}
$$

$\theta_{T}$ gives a direct access to the extent of folding of an oligonucleotide (1: all molecules entirely folded, 0: all molecules entirely unfolded), allows to visually assess the $T_{m}\left(\theta_{t}=0.5\right)$, and normalize the data of different samples (and therefore different absorbances) to a common y-scale (34). For the non-linear fitting and the folded fraction calculation to be carried out, the data must contain both lower and higher baselines. When this was not the case (the oligonucleotide is too stable or unstable), the melting curves were simply normalized to [0;1], and no thermodynamic quantities were determined.

The derivation of Equation (3) and its implementation in the g4dbr application are provided in the g4dbr manual (Supporting information).

\section{Nuclear magnetic resonance (NMR)}

All ${ }^{1} \mathrm{H}-\mathrm{NMR}$ experiments were carried out on a Bruker 700 $\mathrm{MHz}$ spectrometer (Bruker biospin) equipped with $5 \mathrm{~mm}$ TXI probe at $25^{\circ} \mathrm{C}$. The jump-and-return water suppression is used in all experiments (35). The sweep widths were 20 ppm with a 3-sec relaxation delay with a size of $32 \mathrm{~K}$ data points per 1D spectra. The number of scans and dummy scans was 128 and 16 respectively. The $1 \mathrm{D}$ raw data were processed and analyzed with Topspin 4.06 software inbuilt with the instrument. All the quadruplex sequences were 100 $\mu \mathrm{M}$ strand concentration in $100 \mathrm{mM}$ TMAA $+1 \mathrm{mM} \mathrm{KCl}$ in a $5 \mathrm{~mm}$ NMR tube (Wilmad from CortecNet, France).

\section{Electrospray mass spectrometry (ESI-MS)}

All ESI-MS experiments were performed in negative ion mode on an Agilent 6560 IMS-Q-TOF (Agilent Technologies, Santa Clara, CA, USA) with a dual ESI source and soft tuning conditions (36). The experiments were performed in ion mobility mode $\left(p_{\mathrm{He}}=3.89 \pm 0.01\right.$ torr, $T=296 \pm 1$ $\mathrm{K})$. The source gas temperature was $200^{\circ} \mathrm{C}$ with fragmentor voltage at $350 \mathrm{~V}$ (soft conditions, by default). The injected DNA concentrations were $10 \mu \mathrm{M}$ G-quadruplex in $100 \mathrm{mM}$ TMAA and $1 \mathrm{mM} \mathrm{KCl}(180 \mu \mathrm{L} / \mathrm{h}$ flow rate with a syringe pump). The mass spectra and the arrival time distributions for the 5-ions recorded at a drift voltage of $390 \mathrm{~V}$ (drift tube entrance: $600 \mathrm{~V}$; drift tube exit: $210 \mathrm{~V}$ ) are described herein. A separate paper will describe the full dataset (all charge states, various conditions, conversion to collision cross section distributions and comparison with 3D models).

\section{Data processing, app and database}

Circular dichroism, UV-melting, NMR, and native ESIMS data filtering, normalization, fitting, and labeling was performed in g4db, an in-house Shiny application included in the g4dbr package, written in RStudio 1.3.1056 (http://www.rstudio.com), running R 4.1 (https://www.Rproject.org). The database is included in the $g 4 d b r$ package (https://github.com/EricLarG4/g4dbr) and can be explored online (https://ericlarg4.github.io/G4_database.html; http: //doi.org/10.5281/zenodo.4200176). The application documentation is provided in supporting information.

\section{RESULTS}

\section{Database composition and building}

We examined 28 sequences (among which 10 human telomeric variants) for which a specific intramolecular G4 structures had been solved by NMR in high $\mathrm{KCl}$ concentration (usually $\sim 100 \mathrm{mM}$ ), with the exception of the two polymorphic sequences $22 \mathrm{AG}$ and $21 \mathrm{G}$. The sequences will be referred to by their PDB code as listed in Table 1 (see also Supplementary Tables S2-S29). The CD, ${ }^{1} \mathrm{H}$ NMR, ESIMS spectra and UV thermal denaturation profiles are all shown in the supporting information (Supplementary Figures S1-S168).

Our goal was to gather diverse topologies from the literature with NMR data in potassium. The published solution structures in potassium include many parallel topologies with type I base stacking (homo stacking), some hybrid topologies (in particular, among human telomeric sequences) with type II stacking (homo and hetero stacking), some antiparallel topologies with two G-quartets (type III stacking, hetero stacking), and one antiparallel topology with 3-quartet but a type II stacking (5YEY) (Figure 1A- 

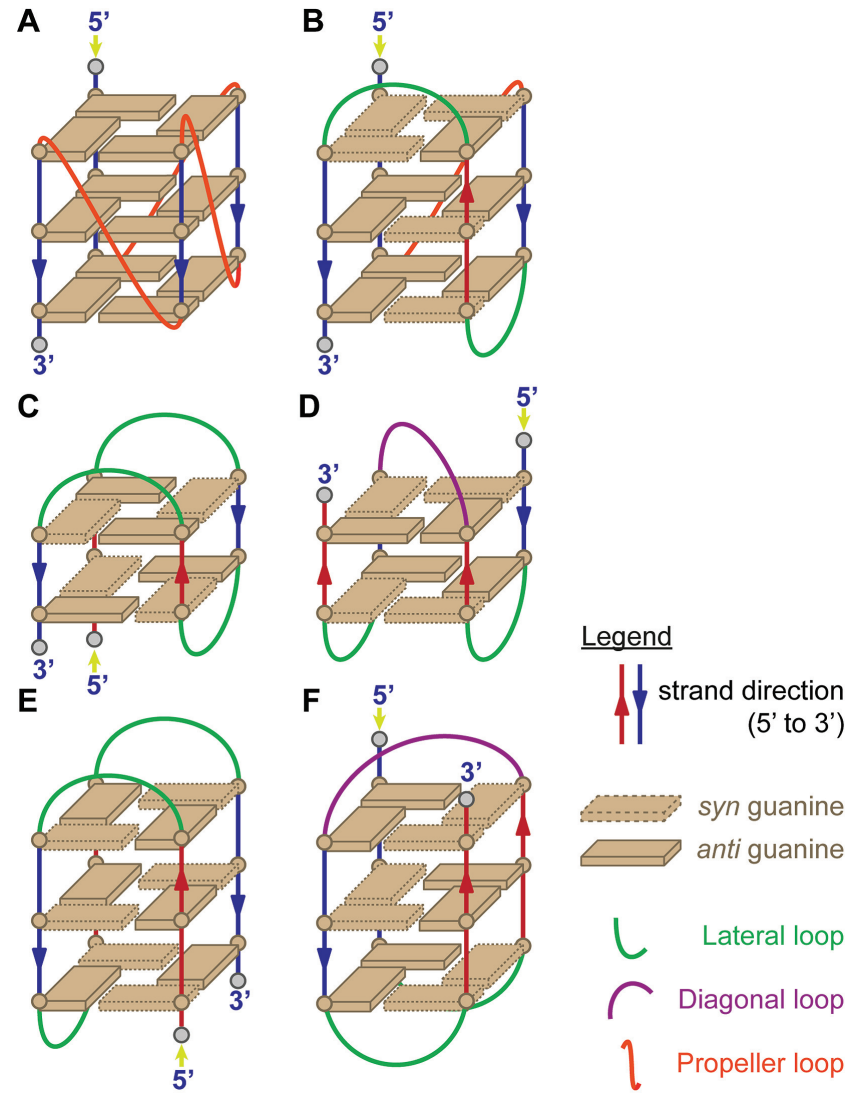

Figure 1. Schematic representation of different G4 topologies. (A) Parallel (type I stacking), (B) Hybrid (type II stacking), (C) Antiparallel 2-quartet (type III stacking with chair conformation), (D) Antiparallel 2-quartet (type III stacking with basket conformation), (E) Antiparallel 3-quartet (type II stacking with chair conformation), (F) Antiparallel 3-quartet (type III stacking with basket conformation, not represented in our database).

E). There is no documented antiparallel topology with 3quartets and a purely type III stacking in potassium; such structures are documented only in sodium (Figure 1F) (37).

The database was built using an in-house, open-source $\mathrm{R}$ package, g4dbr (https://github.com/EricLarG4/g4dbr). Specifically, the $g 4 d b$ function is dedicated to the processing, tidying, storing, visualization, and reporting of $\mathrm{CD}$, ${ }^{1} \mathrm{H}$ NMR, UV-melting and native MS data from oligonucleotide samples. Although developed for the G4 forming sequences characterized in this manuscript, $g 4 d b$ can be used with any nucleic acid sequence. The long-term goal is to provide open-source tools for the deposition of oligonucleotide biophysics data (raw and processed), while allowing for easy and versatile visualization and reporting.

In practice, users can employ the app to visualize a database previously generated by $g 4 \mathrm{db}$ in the database module, or visualize and process raw data, then import it into a new or existing database using the importR module (Supplementary Figure S169). To read raw data in $g 4 d b$, it must be first pasted into a templated Excel file provided in the package. Several tools are included in the package for the automated processing of data, and can also be used outside of the database scope. The most notable are:
- Data filtering by oligonucleotide name, sequence, topology, buffer, cation, and selective writing to databases;

- Labeling of MS spectra performed from user-supplied species names, for which the expected $\mathrm{m} / \mathrm{z}$ are calculated by the application;

- Calculation of molar extinction coefficients at $260 \mathrm{~nm}$ from the oligonucleotide sequence, using Equation (1). This can be used independently from $\mathrm{g} 4 \mathrm{db}$, using the $e p$ silon.calculator function (included in the g4dbr package);

- Conversion of CD data in mdeg to molar extinction coefficient, using Equation (2);

- Determination of folded fraction versus temperature, and $T_{\mathrm{m}}$, from UV-melting data (melt $R$ module), using Equation (3). This will be released as a standalone application, and its performance will be discussed in a separate publication;

- MS noise reduction by intensity filtering, which can be carried out independently with the mass. diet function (included in the package).

The processed data is consolidated into .Rda files, which can either be consulted in $g 4 d b$, or can be loaded in base $\mathrm{R}$ for uses outside the application scope. In $g 4 d b$, the data can be visualized with several customizable plots, and exported in reports in word, pdf, or HTML formats. The reports generated for the oligonucleotides characterized herein are collated in supporting information, and are accessible online as well (https://ericlarg4.github.io/G4_database.html). The use of $\mathrm{g} 4 \mathrm{db}$ is described in supporting information (Supplementary Figures S170 - S192) and the whole application can be found in the Zenodo repository (http://doi.org/10. 5281/zenodo.4200176).

\section{Stability in ESI-MS conditions $(1 \mathrm{mM} \mathrm{KCl} / 100 \mathrm{mM}$ TMAA) compared to $\sim 100 \mathrm{mM} \mathrm{KCl}$}

The melting temperatures are systematically lower in $1 \mathrm{mM}$ $\mathrm{KCl}$ than in $\sim 100 \mathrm{mM} \mathrm{KCl}$ for all sequences studied (see Table 1). As a result, for some molecular systems the decrease is such that a fraction of the oligonucleotide is not folded at room temperature. In the ESI-MS spectra, this translates into the appearance of peaks with lower-thanpredicted number of $\mathrm{K}^{+}$ions bound. The number of $\mathrm{K}^{+}$ ions predicted to bind in the G-quadruplex core is $n$ - 1 , with $n$ the number of stacked G-quartets. However, whether all sites are fully filled depends on the $\mathrm{K}^{+}$binding equilibrium constants and on the $\mathrm{KCl}$ concentration.

Figure 2 shows that for the 3 -quartet G4s, there is a good correlation between the melting temperature, the fraction folded at $25^{\circ} \mathrm{C}$ and the relative intensity of the 2$\mathrm{K}^{+}$complex in the ESI-MS conditions (values in Table 1, spectra in the supporting information). The $2-\mathrm{K}^{+}$abundance increases with the folded fraction or $T_{\mathrm{m}}$ for 3-quartet G4s. Usually, if $T_{\mathrm{m}}>40^{\circ} \mathrm{C}$ (which corresponds to fraction folded at $25^{\circ} \mathrm{C}>80 \%$ ), there is no zero-potassium (non-folded) form in ESI-MS conditions. Slight outliers are 2M27, 2KPR and 5YEY where there is still 9\%,14\% and $16 \% 1-\mathrm{K}^{+}$complex although the fraction folded at $25^{\circ} \mathrm{C}$ is calculated as $\sim 99 \%, 100 \%$ and $100 \%$ respectively (square box in Figure 2, bottom panel). More obvious outliers are $2 \mathrm{LBY}, 5 \mathrm{NYS}, 2 \mathrm{LOD}$ and $2 \mathrm{KYP}$, for which the com- 


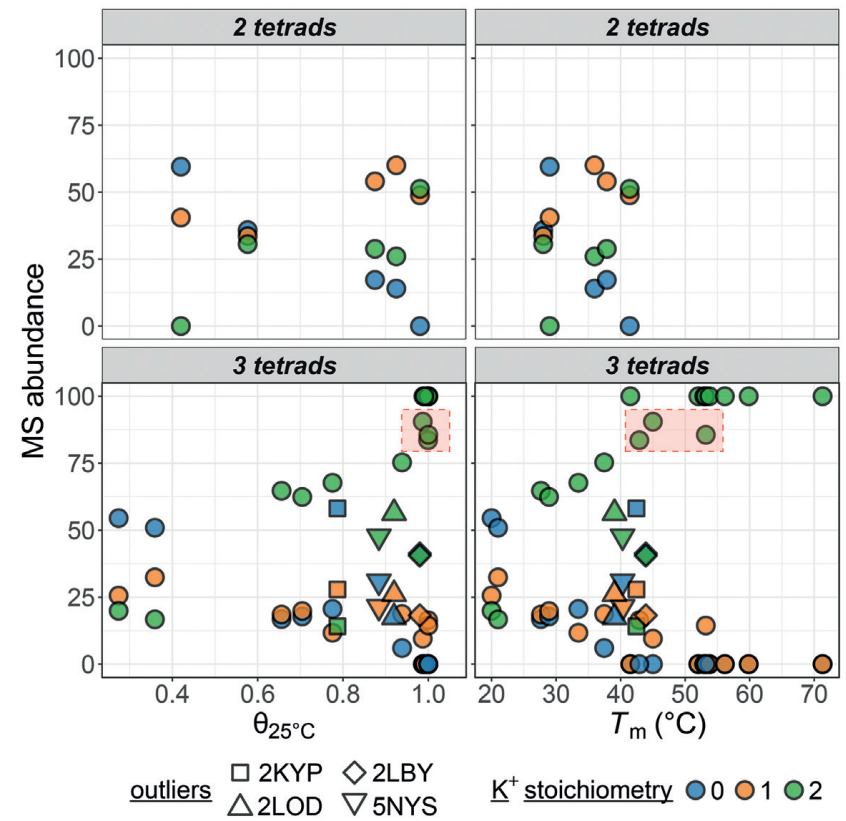

Figure 2. Species abundance (\%) on the 5- charge state in native ESI-MS experiments against their folded fraction at $25^{\circ} \mathrm{C}$ (left) or melting temperature (right) determined by UV-melting. The oligonucleotides are grouped in panels by their number of G-quartets, and colored by their number of potassium adducts. The $2-\mathrm{K}^{+}$data of slight outliers (2M27, 2KPR and $5 \mathrm{YEY}$ ) is framed in red, while four other outliers are distinguished by specific symbols.

bined abundance of $0-\mathrm{K}^{+}$and $1-\mathrm{K}^{+}$complex is $>40 \%$ even though according to the low-temperature baseline in UVmelting the structure seems fully formed at room temperature. These results show that under flat UV-melting baselines, several species with different number of tetrads can coexist, and that the transition can thus be due only to one of these species. This would merit further exploration by temperature-resolved mass spectrometry (38).

The trend is similar with $1-\mathrm{K}^{+}$(2-quartet) G4s (Figure 2 , top panel), but fewer data points are available. Note that the interpretation of the $\mathrm{K}^{+}$distribution in antiparallel 2-quartet structures is peculiar. The case of the 2quartet 2KF8 was discussed in detail previously (where it was named 22GT) (22). In 2KF8, the main stoichiometry is $1 \mathrm{~K}^{+}$, and the $2 \mathrm{~K}^{+}$complex reflects a second loweraffinity binding site between a quartet and a triplet, which upon stacking also changes the $\mathrm{CD}$ spectrum. We can thus imagine that in the $1-\mathrm{K}^{+}$complex the G-triple is not structured, while it is present in the $2-\mathrm{K}^{+}$complex. In contrast, sequences that do not involves stable base pairing (triplex or $\mathrm{G}-\mathrm{C}-\mathrm{G}-\mathrm{C})$ above the quartet at $1 \mathrm{mM} \mathrm{K}{ }^{+}(2 \mathrm{KM} 3,5 \mathrm{LQG})$ do not readily bind a second $\mathrm{K}^{+}$ion.

\section{Solution structure in ESI-MS conditions $(1 \mathrm{mM} \mathrm{KCl} / 100$ mM TMAA) compared to $100 \mathrm{mM} \mathrm{K}^{+}$}

The ${ }^{1} \mathrm{H}$ NMR spectra recorded in $1 \mathrm{mM} \mathrm{KCl}$ and $100 \mathrm{mM}$ TMAA were compared to those published in the literature, and all matching peaks (in the imino region) are labeled according to the published base number assignment. In some cases, minor peaks were present (as indicated in the table), but note that in $100 \mathrm{mM} \mathrm{K} \mathrm{K}^{+}$minor other conformations were also noticed for the wild type sequences. In such case we would still conclude that the main topology in ESI-MS conditions is the same as in the PDB.

We then compared the CD spectra obtained in $\sim 100 \mathrm{mM}$ $\mathrm{KCl}$ and in $1 \mathrm{mM} \mathrm{KCl}+100 \mathrm{mM} \mathrm{TMAA}$, and noted when the shapes were identical, showed more homo-stacking (larger relative signal at $260 \mathrm{~nm}$ ) or more hetero-stacking (larger relative signal at $290 \mathrm{~nm}$ ). Parallel topologies show exclusively anti-anti guanine stacking (type I stacking) characterized in $\mathrm{CD}$ spectra by positive maximum at $\sim 265$ $\mathrm{nm}$ and negative maxima at $245 \mathrm{~nm}$. Hybrid G4s combine syn/anti and anti/syn with anti/anti stacking (type II stacking) in the topology which is represented by two positive peaks at 270 and $290 \mathrm{~nm}$ and 1 negative minimum at $245 \mathrm{~nm}$. Antiparallel topologies usually display alternative stacking of syn/anti and anti/syn guanines (type III stacking) leading to the $C D$ positive maxima at $290 \mathrm{~nm}$ and $C D$ negative minima at $260 \mathrm{~nm}$ (39). Shape changes can hint at different structural populations, and when noticed, the confidence in having the same structure in ESI-MS conditions as in the published conditions was lower.

We also analyzed the $2-\mathrm{K}^{+}$form of each sequence by ion mobility spectrometry, to observe if there is one or several conformational ensembles. Figure 3 shows the arrival time distribution measured for the 5- charge state of the 2$\mathrm{K}^{+}$complex (dark blue), compared to the $0-\mathrm{K}^{+}$complex (light grey). In all cases the peak shape differs, indicating a memory of the presence of the G-quadruplex in the $2-\mathrm{K}^{+}$ complexes. However, the interpretation in terms of solution structure is not straightforward, and will be described in more detail in a separate publication. Briefly, the collision cross section values extracted from the arrival time distributions are systematically smaller than those computed from the solution (PDB) coordinates. Gas-phase rearrangements always induce compaction of the 5- charge states $(40,41)$. Sequences with longer loops or overhangs lead to broad ion mobility peaks, due to the various ways the loops can rearrange in the gas-phase. Consequently, sharp peaks are only observed for short sequences $(<20-n t)$, or 21-24-nt sequences wherein loops are specifically locked in by base pairs or triples (for example, 5YEY, $2 \mathrm{MGN}$, or 2GKU), while all 26-nt G-quadruplexes showed broad peaks. When several peaks are observed, it can either mean that a second topology (different G-quartet arrangement) coexists (as described for $2 \mathrm{GKU}(22,42)$ or $2 \mathrm{JSM}(22,43)$, or that a fraction of the population has not all its loop bases locked in at room temperature. In several cases with a second ion mobility peak, minor imino proton peaks are also visible in ${ }^{1} \mathrm{H}$ NMR (2GKU, 2JSM, 2HY9, 2JPZ, 2LOD), but not always (for example the origin of the two mobility peaks for 2KPR is not elucidated). For these reasons, and contrary to our expectations, the ion mobility data was thus found of limited use in the context of validation of the preservation of solution structures in ESI-MS conditions.

In Table 1 we rated each sequence. Two stars (**) means that the folding is $>90 \%$ complete in mainly the same topology as formed by NMR. One star $\left(^{*}\right)$ means that either the folding is incomplete, or that there are doubts that the main topologies formed are the same in 1 and $\sim 100 \mathrm{mM}$ $\mathrm{KCl}$. Sequences with incomplete folding can be problem- 

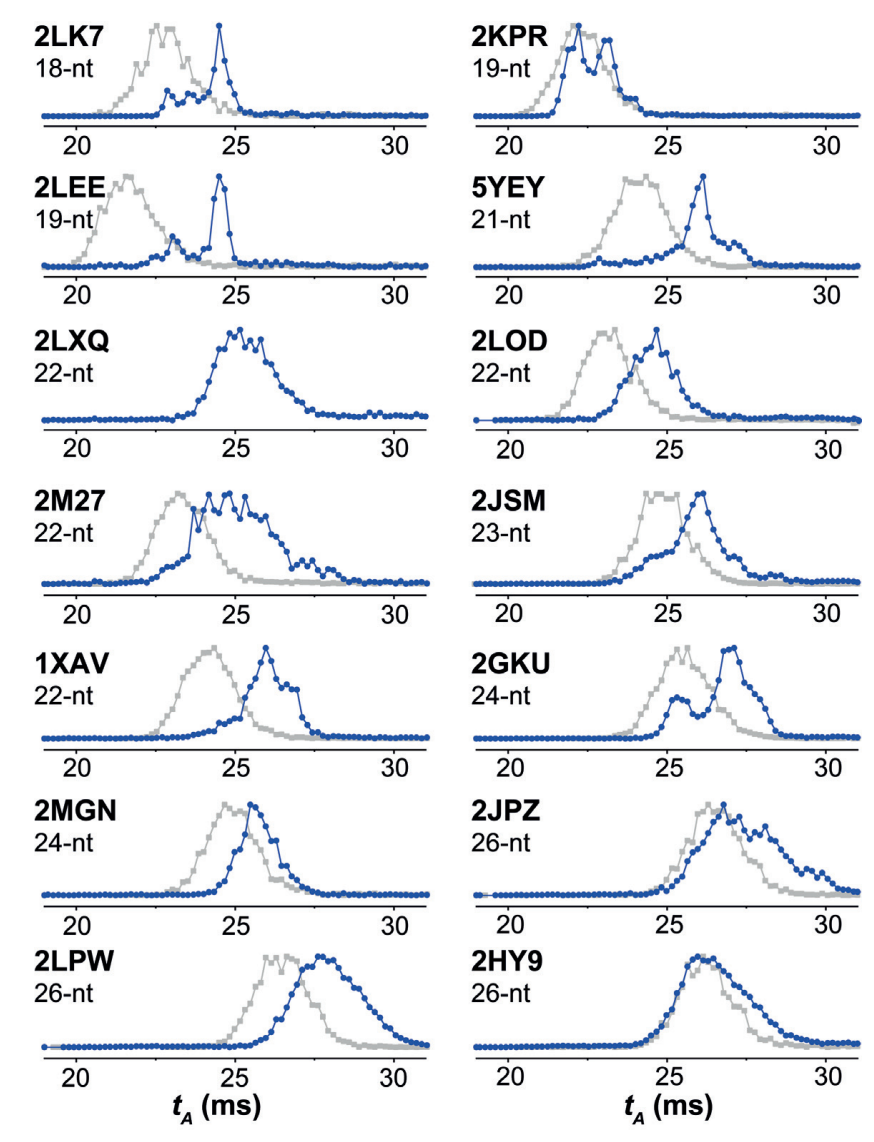

Figure 3. Electrospray ion mobility analysis of the folded form with $2 \mathrm{~K}^{+}$ (blue, recorded from $1 \mathrm{mM} \mathrm{KCl}$ and $100 \mathrm{mM}$ TMAA) and the unfolded form with $0 \mathrm{~K}^{+}$(gray, recorded from $100 \mathrm{mM}$ TMAA) Total arrival time distributions $\left(t_{A}\right)$ of the 5 - charge states for $0 \mathrm{~K}^{+}$and $2 \mathrm{~K}^{+}$complex are shown. The left column gathers representative 3-quartet G4s with type-I stacking and the right column gathers all 3-quartet structures with type-II stacking.

atic for ligand screening by ESI-MS, because ligands that bind to the folded fraction also have to displace the folding equilibrium, and therefore the apparent binding affinity is the convoluted result of folding and binding equilibria. Nevertheless, it is still possible that the folded fraction has the same structure as the $\sim 100 \mathrm{mM} \mathrm{K}^{+}$(NMR) structure, and that these sequences might thus still be of use for structural or specificity studies. Below we discuss the behavior of different G-quadruplex families in more detail.

Human telomeric sequences and variants. Figure 4 gathers the $\mathrm{CD}, \mathrm{NMR}$ and $\mathrm{K}^{+}$adduct distribution of eight models with known structures. This group includes one 3quartet antiparallel topology (5YEY), four 3-quartet hybrid topologies (2JSM, 2GKU, 2HY9 and 2JPZ), and three 2-quartet antiparallel topologies (2KF8, 2KM3, 5LQG). For all hybrid topologies, we observe the 3-quartet $[\mathrm{M}+2 \mathrm{~K}]^{n-}$ complex as the major species in $1 \mathrm{mM} \mathrm{K}^{+}$. However, for hybrid G4 sequences (except $2 \mathrm{GKU}$ ) we observe a substantial population of 2-quartet $[\mathrm{M}+1 \mathrm{~K}]^{n-}$ and nonfolded species $[\mathrm{M}+0 \mathrm{~K}]^{n-}$, indicating an incomplete folding in $1 \mathrm{mM} \mathrm{KCl}$ (2JPZ, 2HY9 and 2JSM) (Figure 4). The subpopulation of minor species is also evident from the unas- signed peaks in the imino region of ${ }^{1} \mathrm{H}-\mathrm{NMR}$ spectra. For hybrid-1 telomeric G4s, the preferred sequences for ligand screening should be 2GKU and 2JSM (the first is more stable and less polymorphic, but the overhangs are not fully faithful to telomeric repeats). For hybrid-2 we have only one sequence representative, 2JPZ, which is incompletely folded $\left(\theta_{25}=0.65\right)$. Therefore, it would be desirable to find another suitable hybrid-2 telomeric sequences, stable enough in ESIMS conditions for ligand screening. Note that there is also evidence of coexistence of hybrid-1 and hybrid-2 topologies $(42,43)$, in line with ion mobility results showing several peaks (see Figure 3 for 2JSM; 2GKU, 2JPZ and the deformed peak for $2 \mathrm{HY} 9$ ).

In antiparallel sequences we have two antiparallel 2quartet sequences with basket topology (2KF8, 5LQG) and one chair topology (2KM3). For 2KM3 and 5LQG, $[\mathrm{M}+1 \mathrm{~K}]^{n-}$ complexes predominate in ESI MS while for $2 \mathrm{KF} 8[\mathrm{M}+1 \mathrm{~K}]^{n-}$ and $[\mathrm{M}+2 \mathrm{~K}]^{n-}$ peaks coexist (Figure 4). The second $\mathrm{K}^{+}$binding site is enabled by the formation of guanine triplet composed of G9, G13, and G21 in the diagonal loop . 5LQG can form two different antiparallel basket-type G4s depending upon $\mathrm{K}^{+}$concentration and $\mathrm{pH}$ as shown previously (44), and is incompletely folded, which makes it unsuitable for ligand screening in MS. Finally, for 5 YEY we observe a major population of $[\mathrm{M}+2 \mathrm{~K}]^{n-}$ and mostly one conformation according to ${ }^{1} \mathrm{H}-\mathrm{NMR}$ spectra. In summary, for antiparallel sequences, the best sequences for ligand screening are 2KF8 (antiparallel 2-quartet, basket) and 5YEY (antiparallel 3-quartet, chair). 2KM3 is the only antiparallel 2-quartet with a chair conformation, but is incompletely folded $\left(\theta_{25}=0.87\right)$.

Two frequently used polymorphic sequences $(21 \mathrm{G}$, $22 \mathrm{AG}$ ) are also included in the database. These sequences show mixed conformational topology from $\mathrm{CD}$ and broad imino proton signal in ${ }^{1} \mathrm{H}$ NMR spectra in the ESI-MS buffer as well. Their mass spectra show both $[\mathrm{M}+1 \mathrm{~K}]^{n-}$ and $[\mathrm{M}+2 \mathrm{~K}]^{n-}(n=4,5,6)$ stoichiometries. Their ion binding distribution and melting temperatures are very similar to those of $2 \mathrm{KF} 8$, indicating significant amounts of 2-quartet topologies in the MS-compatible conditions. Ion mobility spectrometry results are also similar to those of the 2-quartet models (see supporting information Figure S193).

Parallel G-quadruplexes. A second group of nontelomeric (mainly promoter sequences) with validated folds are parallel-stranded with type I stacking. Eight sequences with length ranging from 18 to 26 nucleotides are fully folded $(>90 \%)$ in the ESI-MS conditions. These include two artificial constructs (PDB: 2LK7, 2M4P), two c-myc promoter variants (PDB: $1 \mathrm{XAV}, 2 \mathrm{~A} 5 \mathrm{P} / 2 \mathrm{MGN}$ ), as well as N-myc (PDB: 2LEE), VEGF (PDB: 2M27), Neisseria gonorrhoeae pilE promoters (PDB: 2LXQ) and the CEB25 human minisatellite (PDB: 2LPW) (Figure 5). Another three sequences (2LBY, another c-myc promoter variant; $2 \mathrm{O} 3 \mathrm{M}$, the c-kit promoter; 5NYS, an artificial construct) also form the same parallel structure as reported by NMR, but with a significant fraction unfolded $(0 \mathrm{~K})$. These three sequences should not be used for testing ligand preference to parallel versus other topologies, but can be used with cautious interpretation of the apparent binding constants if one is interested in these specific structures. Finally, 

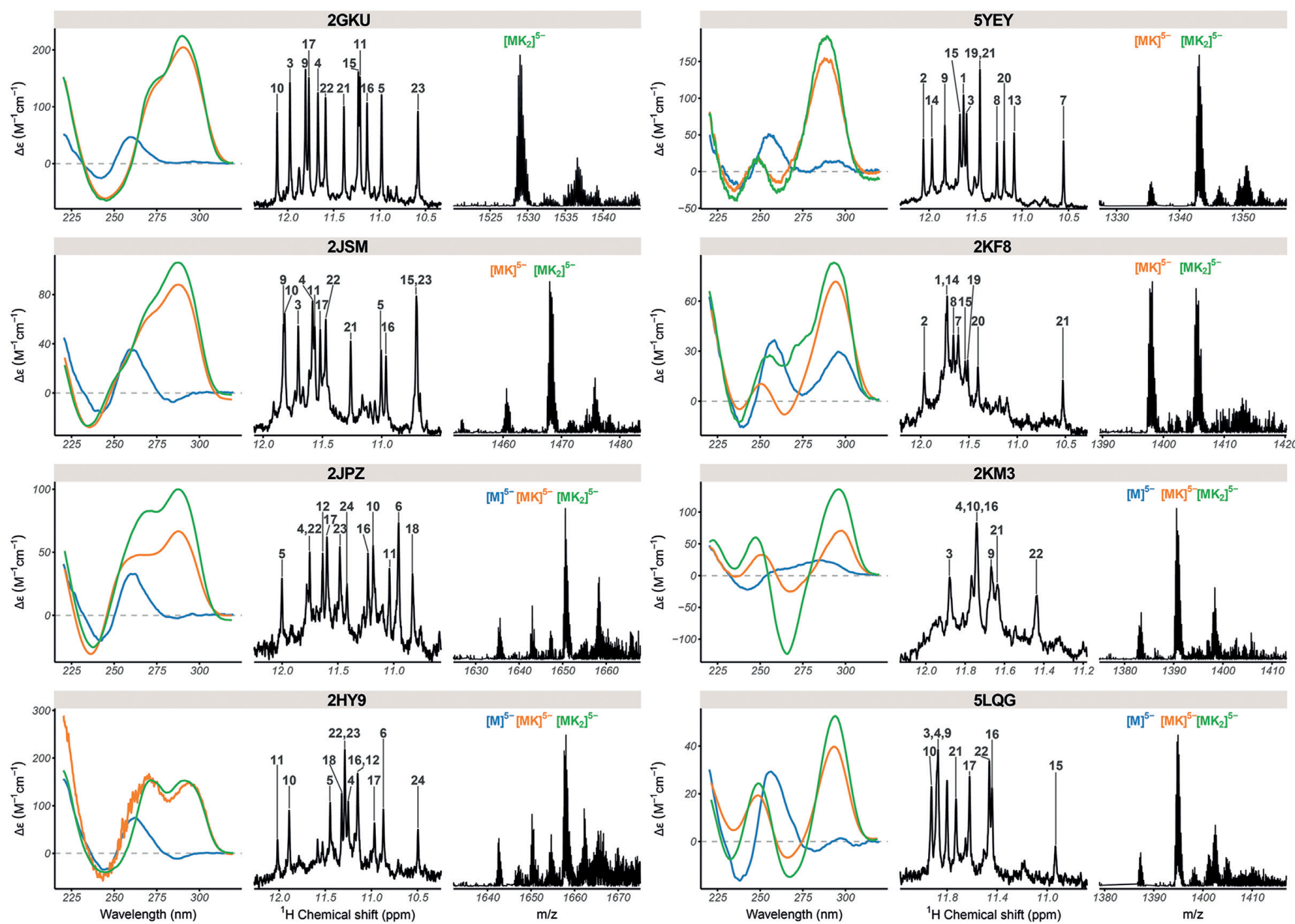

$[\mathrm{MK}]^{5}\left[\mathrm{MK}_{2}\right]^{5-}$

Figure 4. Circular dichroism (left; $10 \mu \mathrm{M}$ DNA in blue: $100 \mathrm{mM}$ TMAA, orange: $100 \mathrm{mM}$ TMAA $+1 \mathrm{mM} \mathrm{KCl}$, green: potassium phosphate $+\mathrm{KCl}$ ), ${ }^{1} \mathrm{H}-\mathrm{NMR}$ (center; $100 \mu \mathrm{M}$ DNA in $100 \mathrm{mM}$ TMAA + $1 \mathrm{mM} \mathrm{KCl}$ ), and native ESI-MS (right; $10 \mu \mathrm{M} \mathrm{DNA}$ in 100 mM TMAA + 1 mM KCl; M: monomer, $\mathrm{K}$ : potassium) data of selected human telomeric quadruplex-forming oligonucleotides.

the c-kit2 (PDB: 2KYP), HIV-1 LTR (PDB: 2N4Y), and KRAS (PDB: 5I2V) do not fold in the desired topology in $1 \mathrm{mM} \mathrm{KCl}$.

Other model structures. To have a few other topologies adequate for ligand screening in ESI-MS, we tested two other 3-quartet hybrid structures (2KPR and 2LOD) and two 2-quartet antiparallel structures (6GZN, HIV-PRO1). The two hybrid folds present both similarities (NMR) and differences (CD) between $100 \mathrm{mM}$ and $1 \mathrm{mM} \mathrm{KCl}$ conditions (Figure 5). Both sequences have a major population of $[\mathrm{M}+2 \mathrm{~K}]^{n-}$, but also $[\mathrm{M}+1 \mathrm{~K}]^{n-}$ as a minor species in $1 \mathrm{mM}$ $\mathrm{K}^{+}$. Therefore, the confidence rating is low ('*') compared to the representatives of type I folding. The two antiparallel structures did not form the same fold in ESI-MS conditions as evident from ${ }^{1} \mathrm{H}$ NMR, CD and ESI-MS.

Recommendations for including further sequences for native MS screening. In order to short-list further sequences for biophysical and ligand screening studies by native mass spectrometry, the following points must be considered:
1. Pre-select sequences that can potentially be of interest due to their origin or biological function, based on the following factors:

a) A high-resolution structure is available (probably by solution $\mathrm{NMR}$ in $\mathrm{K}^{+}$), obtained from a non-modified sequence.

b) The structure does reflect a single or predominant/major conformation in solution.

c) Sequences of the same length but different topology can always be an interesting point to screen for a similar group of ligands to observe 'selectivity'.

2. Perform the experiments and the data processing in a consistent manner to ensure the validity of comparison across techniques and oligonucleotides, and minimize the variability of results.

a) Establish and use standard protocols in each experiment type for all sequences concerned.

b) Where applicable, normalize data to streamline comparisons. For instance, CD data obtained for different oligonucleotide concentrations and/or cuvette path lengths can be more easily compared if the data is converted to $\Delta \varepsilon$ (Equation 2). 

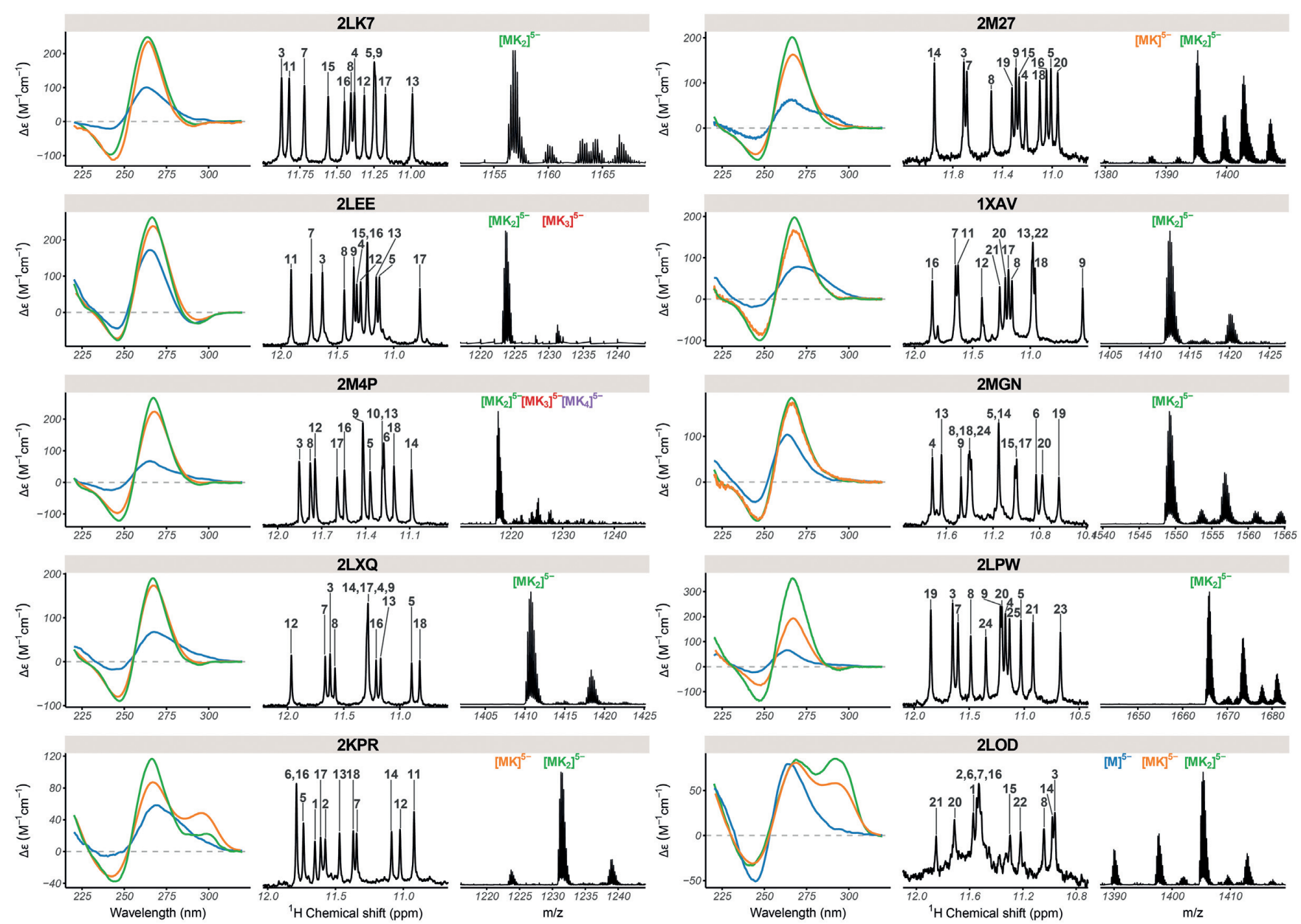

Figure 5. Circular dichroism (left; $10 \mu \mathrm{M}$ DNA in blue: $100 \mathrm{mM}$ TMAA, orange: $100 \mathrm{mM}$ TMAA $+1 \mathrm{mM} \mathrm{KCl}$, green: potassium phosphate $+\mathrm{KCl}$ ), ${ }^{1} \mathrm{H}$ NMR (center; $100 \mu \mathrm{M}$ DNA in $100 \mathrm{mM}$ TMAA + $1 \mathrm{mM} \mathrm{KCl)}$ ), and native ESI-MS (right; $10 \mu \mathrm{M}$ DNA in 100 mM TMAA + 1 mM KCl; M: monomer, $\mathrm{K}$ : potassium) data of selected parallel and hybrid quadruplex-forming oligonucleotides.

c) As far as possible, eliminate human biases from the data processing, by e.g. automation. For instance, the 'manual' baseline subtraction of UV-melting data is notoriously imprecise (34), and was automated herein (Equation 3).

3. To compare with the high-resolution structure (NMR derived) in high $\mathrm{K}^{+}$containing buffer, it is necessary to perform additional solution spectroscopic experiments (CD, UV melting) in both conditions $\left(1 \mathrm{mM} \mathrm{K}^{+}\right.$and $\geq 1 \mathrm{mM} \mathrm{K}^{+}$). Finally, by comparing imino proton signals in ${ }^{1} \mathrm{H}$ NMR with the published assignment, one can conclude whether a particular sequence retains its same tetrad arrangement or not. ${ }^{1} \mathrm{H}$ NMR can also give some information on the formation of triads/base pairs apart from the quartet formation.

4. Since many G-quadruplexes are polymorphic, at $1 \mathrm{mM}$ $\mathrm{K}^{+}$one often finds minor populations for other misfolded species/alternative conformations. Here we focused on comparing the major species observed in ESIMS (3 quartet for type I and II and 2 quartets for type-III folding) with the major species in ${ }^{1} \mathrm{H}-\mathrm{NMR}$. Ion mobility spectrometry interpretation is still subject to caution.
A single narrow peak indicates one main well-locked conformation, but based on the current understanding of gas-phase rearrangements, interpreting complex mobility patterns in terms of solution conformational ensembles is not recommended. In-depth structural analysis for each of the conformers for every sequence in native MS buffer by solution NMR is preferred but was, however, beyond the scope of the manuscript. Overall, we recommend to discard sequences for which a significant amount of unfolded folded species is found $\left({ }^{1} \mathrm{H}\right.$ NMR not matching with literature, different CD profile, $\theta_{25}<<1$ in UV melting, and high abundance of the 0 $\mathrm{K}^{+}$complex in ESI-MS).

5. Consolidate the data in a way that provides the community with open and easy access to raw and processed data, as well as all necessary contextual elements (e.g. oligonucleotide sequence, extinction coefficient, and concentration, buffer and cation nature and concentration, literature references). Here we developed a database and software suite to automatize the gathering, data treatment, storage, and reporting in a completely open way. 


\section{DISCUSSION}

We here listed sequences with different topology and validated fold (** in Table 1) to be used as targets for ligand screening by native MS. We note however that the database is biased towards parallel 3-quartet structures because (1) they are over-represented among the intramolecular structures solved to date in potassium and (2) they are typically more stable and less polymorphic, and thus more likely to be preserved in $1 \mathrm{mM} \mathrm{KCl}$. For non-parallel structures, the best models for ESI-MS screening are variants of the human telomeric sequence, with the known caveat that due to inherent polymorphism, ligand-induced conformational changes can occur even for sequences that have one very predominant fold in absence of ligand $(28,45,46)$.

Finding suitable candidates with intramolecular type II $\&$ type III folding among non-telomeric sequences for MSbased ligand screening in $1 \mathrm{mM} \mathrm{K}{ }^{+}$remains challenging because there are not many such structures solved already in $\sim 100 \mathrm{mM} \mathrm{K}^{+}$. Note that for now we limited our database to intramolecular G-quadruplex forming sequences with all-natural nucleotides. Antiparallel structures with more than two quartets are rare in potassium. Among bimolecular $G$ quadruplex sequences, previous results showed that $(12 \mathrm{TAG})_{2}$ and $\left(\mathrm{G}_{4} \mathrm{~T}_{4} \mathrm{G}_{3}\right)_{2}$ are not stable enough in 1 $\mathrm{mM} \mathrm{K}+(46,47)$, but $\left(\mathrm{dG}_{4} \mathrm{~T}_{4} \mathrm{G}_{4}\right)_{2}$ and $\left(\mathrm{dG}_{4} \mathrm{~T}_{3} \mathrm{G}_{4}\right)_{2}$ shows $[\mathrm{M}+3 \mathrm{~K}]^{n-}$ as major peaks corresponding to 4 quartet antiparallel conformation while $\left(\mathrm{G}_{3} \mathrm{~T}_{4} \mathrm{G}_{4}\right)_{2}$ form $(\mathrm{M}+2 \mathrm{~K})^{n-}$ in $1 \mathrm{mM} \mathrm{KCl}$. Whether these structures are the same as in solution NMR studies $(24,46,48,49)$ remains to be established. The other possibility for expanding the conformational space is to use ammonium acetate $\left(\mathrm{NH}_{4} \mathrm{OAc}\right)$ when there is sufficient evidence of conformation and $\mathrm{NH}_{4}{ }^{+}$ binding from solution NMR studies (24). We will continue to update the database and, in particular, we will incorporate more sequences with unusual quadruplex folding (e.g. left-handed quadruplex, quadruplex-duplex hybrid) and bimolecular/tetra molecular quadruplexes in our online database to have a robust library of G4s.

\section{DATA AVAILABILITY}

The reports generated for the oligonucleotides characterized herein are accessible online as well (https://ericlarg4. github.io/G4_database.html). The whole application is deposited to Zenodo repository (DOI: 10.5281/zenodo. 4200176).

\section{SUPPLEMENTARY DATA}

Supplementary Data are available at NAR Online.

\section{ACKNOWLEDGEMENTS}

This work was financially supported by the European Union (H2020-MSCA-IF-2017-799695-CROWDASSAY and ERC-2013-CoG-616551-DNAFOLDIMS), and benefited from access to NMR, MS and CD at the Plateforme de BioPhysico-Chimie Structurale of the IECB, which staff is acknowledged for their support. Prof. J.L. Mergny and his group are acknowledged for access to SAFAS spectrophotometer. The authors acknowledge Dr Samir Amrane and Dr Frédéric Rosu for useful discussions.

\section{FUNDING}

European Union [H2020-MSCA-IF-2017-799695-CRO WDASSAY and ERC-2013-CoG-616551-DNAFOLDIM S]. Funding for open access charge: INSERM. Conflict of interest statement. None declared.

\section{REFERENCES}

1. Saenger,W. (1984) In: Principles of Nucleic Acid Structure, Springer Science \& Business Media, NY.

2. Choi,J. and Majima,T. (2011) Conformational changes of non-B DNA. Chem. Soc. Rev., 40, 5893-5909.

3. Rhodes,D. and Lipps,H.J. (2015) G-quadruplexes and their regulatory roles in biology. Nucleic. Acids. Res., 43, 8627-8637.

4. Huppert,J.L. (2008) Four-stranded nucleic acids: structure, function and targeting of G-quadruplexes. Chem. Soc. Rev., 37, 1375-1384.

5. Cahoon,L.A. and Seifert,H.S. (2009) An alternative DNA structure is necessary for pilin antigenic variation in Neisseria gonorrhoeae. Science, 325, 764-767.

6. Collie,G.W. and Parkinson,G.N. (2011) The application of DNA and RNA G-quadruplexes to therapeutic medicines. Chem. Soc. Rev., 40, $5867-5892$.

7. Mergny,J.-L. and Hélène,C. (1998) G-quadruplex DNA: a target for drug design. Nat. Med., 4, 1366-1367.

8. Balasubramanian,S. and Neidle,S. (2009) G-quadruplex nucleic acids as therapeutic targets. Curr. Opin. Chem. Biol., 13, 345-353.

9. Yatsunyk,L.A., Mendoza,O. and Mergny,J.-L. (2014) 'Nano-oddities': unusual nucleic acid assemblies for DNA-based nanostructures and nanodevices. Acc. Chem. Res., 47, 1836-1844.

10. Mergny,J.-L. and Sen,D. (2019) DNA quadruple helices in nanotechnology. Chem. Rev., 119, 6290-6325.

11. Bates,P.J., Reyes-Reyes,E.M., Malik,M.T., Murphy,E.M., O'Toole,M.G. and Trent,J.O. (2017) G-quadruplex oligonucleotide AS1411 as a cancer-targeting agent: Uses and mechanisms General subjects. Biochim. Biophys. Acta Gen. Subj., 1861, 1414-1428.

12. Carvalho,J., Paiva,A., Campello,M.P.C., Paulo,A., Mergny,J.-L., Salgado,G.F., Queiroz,J.A. and Cruz,C. (2019) Aptamer-based targeted Delivery of a G-quadruplex Ligand in Cervical Cancer Cells. Sci. Rep., 9, 7945.

13. Neidle,S. and Parkinson,G.N. (2003) The structure of telomeric DNA. Curr. Opin. Struct. Biol., 13, 275-283.

14. Webba da Silva,M. (2007) Geometric formalism for DNA quadruplex folding. Chem. Eur. J., 13, 9738-9745.

15. Karsisiotis,A.I., O'Kane,C. and da Silva,M.W. (2013) DNA quadruplex folding formalism-a tutorial on quadruplex topologies. Methods, 64, 28-35.

16. Neidle,S. (2010) Human telomeric G-quadruplex: The current status of telomeric G-quadruplexes as therapeutic targets in human cancer. FEBS J., 277, 1118-1125.

17. Phan,A.T. (2010) Human telomeric G-quadruplex: structures of DNA and RNA sequences. FEBS J., 277, 1107-1117.

18. Largy,E., Mergny,J.-L. and Gabelica,V. (2016) In: The Alkali Metal Ions: Their Role for Life. Springer, pp. 203-258.

19. Largy,E., Marchand,A., Amrane,S., Gabelica,V. and Mergny,J.-L. (2016) Quadruplex turncoats: cation-dependent folding and stability of quadruplex-DNA double switches. J. Am. Chem. Soc., 138, 2780-2792.

20. Parkinson,G.N., Lee,M.P. and Neidle,S. (2002) Crystal structure of parallel quadruplexes from human telomeric DNA. Nature, $\mathbf{4 1 7}$ 876-880.

21. Wang,Y. and Patel,D.J. (1993) Solution structure of the human telomeric repeat d[AG3(T2AG3)3] G-tetraplex. Structure, 1, 263-282.

22. Marchand,A. and Gabelica,V. (2016) Folding and misfolding pathways of G-quadruplex DNA. Nucleic Acids Res., 44, 10999-11012. 
23. Marchand,A. and Gabelica,V. (2014) Native electrospray mass spectrometry of DNA G-quadruplexes in potassium solution. J. Am. Soc. Mass. Spectrom., 25, 1146-1154.

24. Balthasart,F., Plavec,J. and Gabelica,V. (2013) Ammonium ion binding to DNA G-quadruplexes: do electrospray mass spectra faithfully reflect the solution-phase species? J. Am. Soc. Mass. Spectrom., 24, 1-8.

25. Marchand,A., Ferreira,R., Tateishi-Karimata,H., Miyoshi,D., Sugimoto,N. and Gabelica,V. (2013) Sequence and solvent effects on telomeric DNA bimolecular G-quadruplex folding kinetics. J. Phys. Chem. B, 117, 12391-12401.

26. Rosu,F., Gabelica,V., Houssier,C., Colson,P. and Pauw,E.D. (2002) Triplex and quadruplex DNA structures studied by electrospray mass spectrometry. Rapid Commun. Mass Spectrom., 16, 1729-1736.

27. Gros,J., Rosu,F., Amrane,S., De Cian,A., Gabelica,V., Lacroix,L. and Mergny,J.-L. (2007) Guanines are a quartet's best friend: impact of base substitutions on the kinetics and stability of tetramolecular quadruplexes. Nucleic. Acids. Res., 35, 3064-3075.

28. Marchand,A., Granzhan,A., Iida,K., Tsushima,Y., Ma,Y., Nagasawa,K., Teulade-Fichou,M.-P. and Gabelica,V. (2015) Ligand-induced conformational changes with cation ejection upon binding to human telomeric DNA G-quadruplexes. J. Am. Chem. Soc., 137, 750-756.

29. Marchand,A., Rosu,F., Zenobi,R. and Gabelica,V. (2018) Thermal denaturation of DNA G-quadruplexes and their complexes with ligands: thermodynamic analysis of the multiple states revealed by mass spectrometry. J. Am. Chem. Soc., 140, 12553-12565.

30. Scalabrin,M., Palumbo,M. and Richter,S.N. (2017) Highly improved electrospray ionization-mass spectrometry detection of G-quadruplex-folded oligonucleotides and their complexes with small molecules. Anal. Chem., 89, 8632-8637.

31. Ferreira,R., Marchand,A. and Gabelica,V. (2012) Mass spectrometry and ion mobility spectrometry of G-quadruplexes. A study of solvent effects on dimer formation and structural transitions in the telomeric DNA sequence d (TAGGGTTAGGGT). Methods, 57, 56-63.

32. Cantor,C.R., Warshaw,M.M. and Shapiro,H. (1970) Oligonucleotide interactions. III. Circular dichroism studies of the conformation of deoxyoligonucleolides. Biopolymers, 9, 1059-1077.

33. Tataurov,A.V., You,Y. and Owczarzy,R. (2008) Predicting ultraviolet spectrum of single stranded and double stranded deoxyribonucleic acids. Biophys. Chem., 133, 66-70.

34. Mergny,J.-L. and Lacroix,L. (2003) Analysis of thermal melting curves. Oligonucleotides, 13, 515-537.

35. Plateau,P. and Gueron,M. (1982) Exchangeable proton NMR without base-line distorsion, using new strong-pulse sequences. $J$. Am. Chem. Soc., 104, 7310-7311.

36. Gabelica,V., Livet,S. and Rosu,F. (2018) Optimizing native ion mobility Q-TOF in helium and nitrogen for very fragile noncovalent structures. J. Am. Soc. Mass. Spectrom., 29, 2189-2198.

37. Dvorkin,S.A., Karsisiotis,A.I. and da Silva,M.W. (2018) Encoding canonical DNA quadruplex structure. Sci. Adv., 4, eaat 3007.

38. Marchand,A., Rosu,F., Zenobi,R. and Gabelica,V. (2018) Thermal denaturation of DNA G-quadruplexes and their complexes with ligands: thermodynamic analysis of the multiple states revealed by mass spectrometry. J. Am. Chem. Soc., 140, 12553-12565.

39. Karsisiotis,A.I., Hessari,N.M., Novellino,E., Spada,G.P., Randazzo,A. and Webba da Silva,M. (2011) Topological characterization of nucleic acid G-quadruplexes by UV absorption and circular dichroism. Angew. Chem. Int. Ed., 123, 10833-10836.

40. D'Atri,V. and Gabelica,V. (2019) DNA and RNA telomeric G-quadruplexes: what topology features can be inferred from ion mobility mass spectrometry? Analyst, 144, 6074-6088.

41. Porrini,M., Rosu,F., Rabin,C., Darre,L., Gomez,H., Orozco,M. and Gabelica,V. (2017) Compaction of duplex nucleic acids upon native electrospray mass spectrometry. ACS Cent. Sci., 3, 454-461.

42. Bessi,I., Jonker,H.R., Richter,C. and Schwalbe,H. (2015) Involvement of long-lived intermediate states in the complex folding pathway of the human telomeric G-quadruplex. Angew. Chem. Int. Ed., 54, 8444-8448.

43. Frelih,T., Wang,B., Plavec,J. and Šket,P. (2020) Pre-folded structures govern folding pathways of human telomeric G-quadruplexes. Nucleic Acids Res., 48, 2189-2197.
44. Galer,P., Wang,B., Šket,P. and Plavec,J. (2016) Reversible pH switch of two-quartet G-quadruplexes formed by human telomere. Angew. Chem., 128, 2033-2037.

45. Marchand,A., Strzelecka,D. and Gabelica,V. (2016) Selective and cooperative ligand binding to antiparallel human telomeric DNA G-quadruplexes. Chemistry, 22, 9551-9555.

46. Lecours,M.J., Marchand,A., Anwar,A., Guetta,C., Hopkins,W.S. and Gabelica,V. (2017) What stoichiometries determined by mass spectrometry reveal about the ligand binding mode to G-quadruplex nucleic acids. Biochim. Biophys. Acta Gen. Subj., 1861, 1353-1361.

47. Phan,A.T. and Patel,D.J. (2003) Two-repeat human telomeric d(TAGGGTTAGGGT) sequence forms interconverting parallel and antiparallel G-quadruplexes in solution: distinct topologies, thermodynamic properties, and folding/unfolding kinetics. $\mathrm{J}$. Am. Chem. Soc., 125, 15021-15027.

48. Šket,P., Črnugelj,M. and Plavec,J. (2004) d (G3T4G4) forms unusual dimeric G-quadruplex structure with the same general fold in the presence of $\mathrm{K}+, \mathrm{Na}+$ or $\mathrm{NH} 4+$ ions. Biorg. Med. Chem., 12, $5735-5744$.

49. Schultze,P., Smith,F.W. and Feigon,J. (1994) Refined solution structure of the dimeric quadruplex formed from the Oxytricha telomeric oligonucleotide d (GGGGTTTTGGGG). Structure, 2, 221-233.

50. Luu,K., Phan,A., Kuryavyi,V., Lacroix,L. and Patel,D. (2006) Monomeric Human Telomere DNA Tetraplex with 3+ 1 Strand Fold Topology, Two Edgewise Loops and Double-Chain Reversal Loop, NMR, 12 Structures. J. Am. Chem. Soc, 128, 9963-9970.

51. Phan,A.T., Kuryavyi,V., Luu,K.N. and Patel,D.J. (2007) Structure of two intramolecular G-quadruplexes formed by natural human telomere sequences in $\mathrm{K}+$ solution. Nucleic. Acids. Res., 35, 6517-6525.

52. Dai,J., Carver,M., Punchihewa,C., Jones,R.A. and Yang,D. (2007) Structure of the Hybrid-2 type intramolecular human telomeric G-quadruplex in K+ solution: insights into structure polymorphism of the human telomeric sequence. Nucleic Acids Res., 35, 4927-4940.

53. Dai,J., Punchihewa,C., Ambrus,A., Chen,D., Jones, R.A. and Yang,D. (2007) Structure of the intramolecular human telomeric G-quadruplex in potassium solution: a novel adenine triple formation. Nucleic Acids Res., 35, 2440-2450.

54. Liu,C., Zhou,B., Geng,Y., Tam,D.Y., Feng,R., Miao,H., Xu,N., Shi,X., You,Y., Hong,Y. et al. (2019) A chair-type G-quadruplex structure formed by a human telomeric variant DNA in $\mathrm{K}+$ solution. Chem. Sci., 10, 218-226.

55. Lim,K.W., Amrane,S., Bouaziz,S., Xu,W., Mu,Y., Patel,D.J., Luu,K.N. and Phan,A.T. (2009) Structure of the human telomere in $\mathrm{K}+$ solution: a stable basket-type G-quadruplex with only two G-tetrad layers. J. Am. Chem. Soc., 131, 4301-4309.

56. Lim,K.W., Alberti,P., Guedin,A., Lacroix,L., Riou,J.-F., Royle,N.J., Mergny,J.-L. and Phan,A.T.n. (2009) Sequence variant (CTAGGG)n in the human telomere favors a G-quadruplex structure containing a G. C. G. C tetrad. Nucleic Acids Res., 37, 6239-6248.

57. Micco,M., Collie,G.W., Dale,A.G., Ohnmacht,S.A., Pazitna,I., Gunaratnam,M., Reszka,A.P. and Neidle,S. (2013) Structure-based design and evaluation of naphthalene diimide G-quadruplex ligands as telomere targeting agents in pancreatic cancer cells. J. Med. Chem., 56, 2959-2974.

58. Do,N.Q. and Phan,A.T. (2012) Monomer-dimer equilibrium for the $5^{\prime}-5^{\prime}$ stacking of propeller-type parallel-stranded G-quadruplexes: NMR structural study. Chem. Eur. J., 18, 14752.

59. Trajkovski,M., Webba da Silva,M. and Plavec,J. (2012) Unique structural features of interconverting monomeric and dimeric G-quadruplexes adopted by a sequence from the intron of the N-myc gene. J. Am. Chem. Soc., 134, 4132-4141.

60. Mukundan,V.T. and Phan,A.T. (2013) Bulges in G-quadruplexes: broadening the definition of G-quadruplex-forming sequences. J. Am. Chem. Soc., 135, 5017-5028.

61. Kuryavyi,V., Cahoon,L.A., Seifert,H.S. and Patel,D.J. (2012) RecA-binding pilE G4 sequence essential for pilin antigenic variation forms monomeric and $5^{\prime}$ end-stacked dimeric parallel G-quadruplexes. Structure, 20, 2090-2102.

62. Agrawal,P., Hatzakis,E., Guo,K., Carver,M. and Yang,D. (2013) Solution structure of the major G-quadruplex formed in the human VEGF promoter in $\mathrm{K}+$ : insights into loop interactions of the parallel G-quadruplexes. Nucleic Acids Res., 41, 10584-10592. 
63. Ambrus,A., Chen,D., Dai,J.X., Jones,R.A. and Yang,D. (2005) Solution structure of the biologically relevant G-quadruplex element in the human c-MYC promoter. implications for G-quadruplex stabilization. Biochemistry, 44, 2048-2058.

64. Phan,A.T., Kuryavyi,V., Gaw,H.Y. and Patel,D.J. (2005) Small-molecule interaction with a five-guanine-tract G-quadruplex structure from the human MYC promoter. Nat. Chem. Biol., 1, $167-173$.

65. Chung,W.J., Heddi,B., Hamon,F., Teulade-Fichou,M.P. and Phan,A.T. (2014) Solution Structure of a G-quadruplex Bound to the Bisquinolinium Compound Phen-DC3. Angew. Chem. Int. Ed., 53, 999-1002.

66. Amrane,S., Adrian,M., Heddi,B., Serero,A., Nicolas,A., Mergny,J.-L. and Phan,A.T.n. (2012) Formation of pearl-necklace monomorphic G-quadruplexes in the human CEB25 minisatellite. $J$. Am. Chem. Soc. 134, 5807-5816.

67. Mathad,R.I., Hatzakis,E., Dai,J. and Yang,D. (2011) c-MYC promoter G-quadruplex formed at the 5'-end of NHE III 1 element: insights into biological relevance and parallel-stranded G-quadruplex stability. Nucleic Acids Res., 39, 9023-9033.

68. Phan,A.T., Kuryavyi,V., Burge,S., Neidle,S. and Patel,D.J. (2007) Structure of an unprecedented G-quadruplex scaffold in the human c-kit promoter. J. Am. Chem. Soc., 129, 4386-4392.

69. Trajkovski,M., Endoh,T., Tateishi-Karimata,H., Ohyama,T., Tanaka,S., Plavec,J. and Sugimoto,N. (2018) Pursuing origins of (poly) ethylene glycol-induced G-quadruplex structural modulations. Nucleic Acids Res., 46, 4301-4315.
70. Kuryavyi,V., Phan,A.T. and Patel,D.J. (2010) Solution structures of all parallel-stranded monomeric and dimeric G-quadruplex scaffolds of the human c-kit2 promoter. Nucleic Acids Res., 38, 6757-6773.

71. De Nicola,B., Lech,C.J., Heddi,B., Regmi,S., Frasson,I., Perrone,R., Richter,S.N. and Phan,A.T. (2016) Structure and possible function of a G-quadruplex in the long terminal repeat of the proviral HIV-1 genome. Nucleic Acids Res., 44, 6442-6451.

72. Kerkour,A., Marquevielle,J., Ivashchenko,S., Yatsunyk,L.A., Mergny,J.-L. and Salgado,G.F. (2017) High-resolution three-dimensional NMR structure of the KRAS proto-oncogene promoter reveals key features of a G-quadruplex involved in transcriptional regulation. J. Biol. Chem., 292, 8082-8091.

73. Kuryavyi,V. and Patel,D.J. (2010) Solution structure of a unique G-quadruplex scaffold adopted by a guanosine-rich human intronic sequence. Structure, 18, 73-82.

74. Marušič,M., Šket,P., Bauer,L., Viglasky,V. and Plavec,J. (2012) Solution-state structure of an intramolecular G-quadruplex with propeller, diagonal and edgewise loops. Nucleic Acids Res., 40, 6946-6956.

75. Amrane,S., Kerkour,A., Bedrat,A., Vialet,B., Andreola,M.-L. and Mergny,J.-L. (2014) Topology of a DNA G-quadruplex structure formed in the HIV-1 promoter: a potential target for anti-HIV drug development. J. Am. Chem. Soc., 136, 5249-5252.

76. Lenarčič Živković,M., Rozman,J. and Plavec,J. (2018) Adenine-driven structural switch from a two-to three-quartet DNA G-quadruplex. Angew. Chem. Int. Ed., 57, 15395-15399. 